\title{
FULL SCALE REGENERABLE HEPA FILTER DESIGN USING SINTERED METAL FILTER ELEMENTS
}

FINAL TECHNICAL REPORT

Reporting Period Start Date: April 30, 1999

Reporting Period End Date: November 30, 2002

Authors: Gil Ramos, Mott Corporation

Kenneth Rubow, PhD, Mott Corporation

Ronald Sekellick, Consultant to Mott

DATE ISSUED: November 27, 2002

\author{
US DEPARTMENT OF ENERGY \\ FEDERAL ENERGY TECHNOLOGY CENTER \\ 3610 Collins Ferry Road \\ Morgantown, WV 26507-0880 \\ DOE Contract No. DE-AC26-99FT40570
}

Submitting Organization: Mott Corporation

84 Spring Lane

Farmington, CT 06032 
DISCLAIMER: This report was prepared as an account of work sponsored by an agency of the US Government. Neither the Government nor any agency thereof, nor any of their employees, makes any warranty, express or implied, or assumes any legal liability or responsibility for the accuracy, completeness, or usefulness of any information, apparatus, product, or process disclosed, or represents that its use would not infringe privately owned rights. Reference herein to any specific commercial product, process, or service by trade name, trademark, manufacturer, or otherwise does not necessarily constitute or imply its endorsement, recommendation, or favoring by the US Government or any agency thereof. The views and opinions of authors expressed herein do not necessarily state or reflect those of the US Government or any agency thereof. 


\section{ABSTRACT}

A Department of Energy funded contract involved the development of porous metal as a HEPA filter, and the subsequent design of a full-scale regenerable HEPA filtration system (RHFS). This RHFS could replace the glass fiber HEPA filters currently being used on the high level waste (HLW) tank ventilation system with a system that would be moisture tolerant, durable, and cleanable in place. The origins of the contract are a 1996 investigation at the Savannah River Technology Center (SRTC) regarding the use of porous metal as a HEPA filter material. This contract was divided into Phases I, IIA and IIB. Phase I of the contract evaluated simple filter cylinders in a simulated High Level Waste (HLW) environment and the ability to clean and regenerate the filter media after fouling. Upon the successful completion of Phase I, Phase IIA was conducted, which included lab scale prototype testing and design of a full-scale system.

The work completed under Phase IIA included development of a full-scale system design, development of a filter media meeting the HEPA filtration efficiency that would also be regenerable using prescribed cleaning procedures, and the testing of a single element system prototype at Savannah River. All contract objectives were met. The filter media selected was a nickel material already under development at Mott, which met the HEPA filtration efficiency standard. The Mott nickel media met and exceeded the HEPA requirement, providing $99.99 \%$ removal against a requirement of $99.97 \%$. Double open-ended elements of this media were provided to the Savannah River Test Center for HLW simulation testing in the single element prototype filter. These elements performed well and further demonstrated the practicality of a metallic media regenerable HEPA filter system. An evaluation of the manufacturing method on many elements demonstrated the reproducibility to meet the HEPA filtration requirement.

The full-scale design of the Mott RHFS incorporated several important features in its design and operation. The element bundle would be an all welded assembly, which could be removed and replaced as a unit if the elements ever needed replacement. Each element had a spray nozzle mounted above it for cleaning; it could also be cleaned by a soak and backwash technique. The inlet nozzle incorporated a cyclonic separator to initially remove large suspended material and droplets. Tests indicated a significant reduction of dirt load getting to the filter elements, which would extend the operating time between cleanings. A high capacity blower was selected to overcome the higher pressure drop of the metallic elements. The blower, having a 25 horsepower motor, would be capable of operating the system to higher pressure drops than available on the glass fiber HEPA filters. This additional capacity further increases the operating duration of the filter.

Upon successful testing and acceptance of the full-scale design, Phase IIB would involve the construction and test of a full-scale prototype system on an actual HLW tank. Phase IIA was completed but for funding and priority reasons the contract was halted; thus Phase IIB would not be pursued at this time. The Mott RHFS has been proven at each stage of the development process to meet the requirements of a suitable replacement system for the glass fiber HEPA filters enabling great cost savings. It remains to test a full-scale operating system on an actual high level waste tank to fully demonstrate the performance and anticipated cost savings of the Mott RHFS. Mott is confident that the performance will be more than acceptable. 


\section{TABLE OF CONTENTS}

PAGE

1. LIST OF FIGURES AND TABLES

2. INTRODUCTION 6

$\begin{array}{lr}\text { 3. EXECUTIVE SUMMARY } & 7\end{array}$

4. PHASE I DEVELOPMENT AND CONCEPTUAL DESIGN 8

Test and Development Plan $\quad 8$

Results of Mott Laboratory Development: Filter Elements $\quad 8$

Results of WSRC Testing $r$

Conceptual Design of a Mott Regenerable HEPA Filter System 12

5. PHASE IIA FULL SCALE REGENERABLE HEPA FILTER SYSTEM DESIGN 13

Full Scale RHFS Design $\quad 13$

Element Development $\quad 19$

Element Tests at Oak Ridge $\quad 20$

Element Tests at WSRC $\quad 20$

Assessment of Proposed Technology $\quad 21$

Regulatory and Safety $\quad 22$

$\begin{array}{ll}\text { Project Reviews } & 22\end{array}$

6. CONCLUSIONS AND RECOMMENDATIONS 22

7. REFERENCES

8. LIST OF ACRONYMS AND ABBREVIATIONS 24 


\section{LIST OF FIGURES AND TABLES}

PAGE

Figure 4-1 SRTC sludge test data.

Figure 4-2 SRTC road dust test data.

Figure 4-3 SRTC salt test data.

$\begin{array}{ll}\text { Figure 5-1 HEPA filter. } & 14\end{array}$

Figure 5-2 Filter spray nozzle location. 14

Figure 5-3 Hypulse GS filter drawing.

Figure 5-4 Sintered metal element drawing 16

$\begin{array}{ll}\text { Figure 5-5 RHFS schematic diagram. } & 17\end{array}$

$\begin{array}{lr}\text { Figure 5-6 Typical skid layout. } & 18\end{array}$

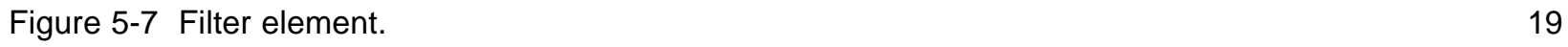

Table 4-1 Phase I Filter Element Data: Element Design 2225372

Table 4-2 Phase I Filter Element Data: Element Design 2225070-010 - 0.047" Media 9

Table 4-3 Phase I Pressure Drop Data: Element Design 2225372-010 - 0.028” Media 9

Table 4-4 Phase I Pressure Drop Data: Element Design 2225070-010 - 0.047" Media 10

$\begin{array}{lll}\text { Table 5-1 Nickel Media Air Flow } & 20\end{array}$ 


\section{INTRODUCTION}

The Savannah River Technology Center (SRTC) began investigating the use of porous metal as a high efficiency particulate air (HEPA) filter material in 1996. The intent was to find a material to replace the glass fiber HEPA filters currently being used on the high level waste (HLW) tank ventilation system that would be moisture tolerant, durable, and cleanable in place. Porous metal filter media from the Mott Corporation, Farmington Connecticut, was tested at Savannah River and passed the di-octyl phthalate (DOP) test for particle retention efficiency. SRTC was provided with two filter elements in November of 1997 for simulation testing. The results of those tests are reported in document WSRC-TR-98-00382 issued in October of 1998. The findings suggested that a full scale HEPA filter utilizing porous metal media was feasible.

A project was funded by Department Of Energy (DOE), Federal Energy Technology Center (FETC) No. DE-RA26-99FT40316, to investigate novel technologies which might be applicable to the RHFS. After evaluation of several proposals, the Mott Corporation was selected to further develop porous metal filter technology and provide a workable prototype system for further evaluation. In 1999 DOE issued Project Number DE-AC26-99FT40570 for a full scale development project consisting of three parts: Phase I to conduct a conceptual design for a Regenerable HEPA Filter System, Phase IIA for the design of a full scale working system, and Phase IIB for the construction and testing of a full scale system on a HLW tank at Savannah River. Under Phase I an acceptable filter media and filter element were to be prepared and tested as well as a conceptual plan for a full-scale operating system. These objectives were met under Phase I. 
Testing was conducted at both the Mott laboratory and SRTC. SRTC conducted challenge testing on small elements with simulated wastes and Mott conducted operational testing of the proposed inside-out filter design. Successful testing led to a contract extension for design and further development of a fullscale prototype under Phase IIA. Once completed, a full-scale system would be tested on a HLW tank under Phase IIB.

Materials development work and system design have been successfully completed through Phase IIA and this report describes the work done to that point. The offered design utilizes experience based on Mott's other types of cleanable filters and employs multiple elements in a single housing capable of being washed down by spray nozzles for cleaning. Filter elements made from nickel are used for the filtration and meet the HEPA filtration criteria required.

The full-scale system has been designed for a HLW tank and consists of the filter, wash system, vacuum blower, and all necessary components for a workable unit. Several design reviews have been conducted and comments and suggestions have been incorporated in the latest design.

\section{EXECUTIVE SUMMARY}

The Savannah River Technology Center (SRTC) began investigating the use of porous metal as a HEPA filter material in 1996. The intent was to find a material to replace the glass fiber HEPA filters currently being used on the high level waste $(\mathrm{HLW})$ tank ventilation system that would be moisture tolerant, durable, and cleanable in place. Porous metal filter media from the Mott Corporation, Farmington Connecticut, was tested and passed the WSRC DOP test for particle retention efficiency. SRTC was provided with two filter elements in November of 1997 for simulation testing. The results of those tests are reported in document WSRC-TR-98-00382 issued in October of 1998. ${ }^{1}$ The findings suggested that a full-scale HEPA filter utilizing porous metal media was feasible.

A Department of Energy funded contract was initiated to evaluate technologies deemed promising to replace the glass fiber HEPA materials. The Mott Corporation was selected to participate in the contract to demonstrate a regenerable HEPA filtration system (RHFS) and develop a full-scale workable design.

Phase I of the contract evaluated simple filter cylinders in a simulated High Level Waste (HLW) environment and the ability to clean and regenerate the filter media after fouling. This was done with sufficient satisfaction to suggest continuation of the program into the next phase.

Phase II was divided up into Phase A and B. Phase IIA would be lab scale prototype testing, and design of a full-scale system. Upon successful testing and acceptance of the full-scale design, Phase IIB would be continued to test a full-scale prototype system on an actual HLW tank. Phase IIA was completed but for funding and priority reasons the program was halted. Phase IIB would not be pursued at this time.

The work completed under Phase IIA consisted of:

-full-scale system design by Mott;

-development of a filter media meeting the HEPA filtration efficiency that would also be regenerable using prescribed cleaning procedures;

-testing of a single element system prototype at Savannah River.

All of these contract objectives were met.

The filter media selected was a nickel material already under development at Mott, which met the HEPA filtration efficiency standard. It had been found that the stainless steel media evaluated in Phase I did not meet the rigorous HEPA test as conducted by Air Techniques International (ATI). The Mott nickel media met and exceeded the HEPA requirement providing 99.99\% removal against a requirement of $99.97 \%$. The media was also modified somewhat to provide better pressure drop. Double open-ended elements of this media were provided to the Savannah River Test Center for HLW simulation testing in the single element prototype filter. These elements performed well and further demonstrated the practicality of a metallic media regenerable HEPA filter system. An evaluation of the manufacturing method on many elements demonstrated the reproducibility to meet the HEPA filtration requirement. 
The full-scale design of the Mott RHFS incorporated several important features in its design and operation. The element bundle would be an all welded assembly, which could be removed and replaced as a unit if the elements ever needed replacement. Each element had a spray nozzle mounted above it for cleaning; it could also be cleaned by a soak and backwash technique. The inlet nozzle incorporated a cyclonic separator to initially remove large suspended material and droplets. Tests indicated a significant reduction of dirt load getting to the filter elements, which would extend the operating time between cleanings.

A high capacity blower was selected to overcome the higher pressure drop of the metallic elements. The blower, having a 25 horsepower motor, would be capable of operating the system to higher pressure drops than available on the glass fiber HEPA filters. This additional capacity further increases the operating duration of the filter.

The Mott RHFS has been proven at each stage of the development process to meet the requirements of a suitable replacement system for the glass fiber HEPA filters enabling great cost savings. It remains to test a full-scale operating system on an actual high level waste tank to fully demonstrate the performance and anticipated cost savings of the Mott RHFS. Mott is confident that the performance will be more than acceptable.

\section{PHASE I DEVELOPMENT AND CONCEPTUAL DESIGN}

\section{Test and Development Plan}

The test plan for the Phase I work was divided between that conducted by SRTC and that conducted by Mott to develop a working full scale RHFS. The work conducted by SRTC was concerned with the performance of the filter media in a simulated challenge test to determine the response of the filter media to filtration of tank waste products and regeneration on cleaning. Work conducted at Mott was concerned with developing a workable design and filter media capable of achieving a HEPA rating.

The SRTC challenge consisted of three types of simulants: waste sludge, South Carolina soil dust, and salt. Each test would run for several hundred hours, depending on the time to reach a plugged condition, in order to perform 5 to 6 cleaning cycles. Flow and pressure drop, recorded against time, were monitored and recorded.

The filter elements tested were small cylinders challenged on the outside and washed with multiple spray nozzles for cleaning.

The tests at Mott were concerned more with the engineering development of a full scale working system and the preparation of a conceptual design. As a conceptual design was developed, it was tested in the Mott Laboratory.

\section{Results of Mott Laboratory Development: Filter Elements}

The SRTC test elements were of the same size as that tested in the 1998 work, 2" diameter by 4" long with a $3 / 4$ " tube for mounting. Initially, 1 micron grade media, 0.028 " thick was used in order to keep pressure drop to a minimum. When one of the two elements failed the DOP test, a second set was made with thicker material, 0.047" thick. These were not used in the evaluation. WSRC DOP testing revealed one passed with $99.99 \%$ efficiency, while the second failed at $99.00 \%$. A left over element from the 1998 work was used in the interest of time. It passed the DOP test at $99.99 \%$ efficiency.

Basic data on the elements provided are presented in Tables 4-1 to 4-4. 
Table 4.1

Phase I Filter Element Data:

Element Design 2225372

\begin{tabular}{|c|c|c|c|c|c|c|}
\hline $\begin{array}{l}\text { Element } \\
\text { Number }\end{array}$ & $\begin{array}{c}\text { Diameter, } \\
\text { INCH }\end{array}$ & $\begin{array}{c}\text { Length, } \\
\text { INCH }\end{array}$ & $\begin{array}{c}\text { Filter Area, } \\
\text { FT2 }\end{array}$ & $\begin{array}{c}\text { Bubblepoint } \\
\text { in. H2O }\end{array}$ & $\begin{array}{c}\text { Pressure } \\
\text { Drop } \\
@ 30 \mathrm{cfm} / \mathrm{ft}^{2}\end{array}$ & $\begin{array}{c}\text { DOP } \\
\text { Efficiency, } \\
\%\end{array}$ \\
\hline 1 & 1.9 & 3.71 & 0.153 & 36.0 & $1.80 \mathrm{psi}$ & 99.95 \\
\hline 2 & 1.95 & 3.72 & 0.158 & 36.7 & $1.85 \mathrm{psi}$ & 99.99 \\
\hline
\end{tabular}

Table 4.2

Phase I Filter Element Data:

Element Design 2225070-010 - 0.047" Media

\begin{tabular}{|c|c|c|c|c|c|c|}
\hline $\begin{array}{l}\text { Element } \\
\text { Number }\end{array}$ & $\begin{array}{c}\text { Diameter, } \\
\text { INCH }\end{array}$ & $\begin{array}{c}\text { Length, } \\
\text { INCH }\end{array}$ & $\begin{array}{c}\text { Filter Area, } \\
\text { FT2 }\end{array}$ & $\begin{array}{c}\text { Bubblepoint } \\
\text { in. H2O }\end{array}$ & $\begin{array}{c}\text { Pressure Drop } \\
@ 30 \mathrm{cfm} / \mathrm{ft}^{\mathrm{f}}\end{array}$ & $\begin{array}{c}\text { DOP } \\
\text { Efficiency, } \\
\%\end{array}$ \\
\hline Nov-97 & & & & & & 99.99 \\
\hline $\mathrm{A}, \quad 7 / 99$ & 1.970 & 3.84 & 0.165 & 36.0 & & 99.00 \\
\hline $\mathrm{B}, \quad 7 / 99$ & 1.970 & 3.82 & 0.164 & 35.0 & & 99.99 \\
\hline
\end{tabular}

Table 4.3

Phase I Pressure Drop Data:

Element Design 2225372-010 - 0.028" Media

\begin{tabular}{|c|c|c|c|c|c|}
\hline $\begin{array}{l}\text { Element } \\
\text { Number }\end{array}$ & FM & $\begin{array}{c}\text { Pressure } \\
\text { Drop, } \\
\text { psi }\end{array}$ & $\begin{array}{c}\text { Air Flow, } \\
\text { SCFM }\end{array}$ & $\begin{array}{c}\text { Air Flow, } \\
\text { ACFM }\end{array}$ & $\begin{array}{c}\text { Face Velocity, } \\
{\mathrm{cfm} / \mathrm{ft}^{2}}^{2}\end{array}$ \\
\hline 1 & 2 & 0.7 & 2.05 & 1.95 & 12.7 \\
\hline & 3 & 1.1 & 3.11 & 2.89 & 18.9 \\
\hline & 4.5 & 1.7 & 4.75 & 4.25 & 27.8 \\
\hline & 6 & 2.2 & 6.43 & 5.59 & 36.5 \\
\hline & 7.5 & 2.8 & 8.18 & 6.87 & 44.9 \\
\hline & 9 & 3.4 & 9.98 & 8.10 & 52.9 \\
\hline
\end{tabular}

\begin{tabular}{|l|c|c|c|c|c|}
\hline 2 & 2 & 0.7 & 2.05 & 1.95 & 12.3 \\
\hline & 3.2 & 1.16 & 3.32 & 3.08 & 19.5 \\
\hline & 4.8 & 1.7 & 5.07 & 4.54 & 28.7 \\
\hline & 6.3 & 2.3 & 6.77 & 5.85 & 37.0 \\
\hline & 8 & 3.0 & 8.78 & 7.29 & 46.1 \\
\hline & 9.6 & 3.6 & 10.71 & 8.60 & 54.4 \\
\hline & & & & &
\end{tabular}


Table 4.4

Phase I Pressure Drop Data:

Element Design 2225070-010 - 0.047" Media

\begin{tabular}{|c|c|c|c|c|c|}
\hline $\begin{array}{l}\text { Element } \\
\text { Number }\end{array}$ & FM & $\begin{array}{c}\text { Pressure } \\
\text { Drop, } \\
\text { psi }\end{array}$ & $\begin{array}{c}\text { Air Flow, } \\
\text { SCFM }\end{array}$ & $\begin{array}{c}\text { Air Flow, } \\
\text { ACFM }\end{array}$ & $\begin{array}{l}\text { Face Velocity, } \\
{\mathrm{cfm} / \mathrm{ft}^{2}}^{2}\end{array}$ \\
\hline$A$ & 2 & 1.0 & 2.06 & 1.93 & 11.7 \\
\hline \multirow{5}{*}{$\begin{array}{l}0.165 \\
\text { FT2) } \\
\end{array}$} & 3 & 1.6 & 3.16 & 2.85 & 17.3 \\
\hline & 4.5 & 2.4 & 4.85 & 4.16 & 25.2 \\
\hline & 6 & 3.25 & 6.62 & 5.40 & 32.7 \\
\hline & 7.5 & 4.1 & 8.48 & 6.60 & 40.0 \\
\hline & 9 & 5.0 & 10.42 & 7.77 & 47.1 \\
\hline$B$ & 2 & 1.0 & 2.06 & 1.93 & 11.8 \\
\hline \multirow{5}{*}{$\begin{array}{c}(0.164 \\
\text { FT2) } \\
\end{array}$} & 3 & 1.6 & 3.16 & 2.85 & 17.4 \\
\hline & 4.5 & 2.4 & 4.85 & 4.16 & 25.4 \\
\hline & 6 & 3.25 & 6.62 & 5.40 & 32.9 \\
\hline & 7.5 & 4.0 & 8.66 & 6.50 & 39.6 \\
\hline & 9 & 4.93 & 10.40 & 7.78 & 47.4 \\
\hline
\end{tabular}

The media being tested was standard 316L stainless steel. This media was successful structurally and regenerated by water washing. However, on analysis, it became apparent that it would not meet the HEPA DOP challenge test, no matter what was done to it, and still achieve acceptable pressure drop.

It was determined that the DOP test conducted at Savannah River was a modified test for the purpose of determining leaks and was not the rigorous test required to evaluate filter media. Testing conducted on the Mott filters and media, by Air Technology International (ATI), determined that the media and elements tested at Savannah River did not meet the HEPA requirement. Further development of the media would be required in order to meet HEPA standards. However, the simulation testing by SRTC was considered valid for filter regeneration purposes.

Due to a limited budget for Phase I no additional media development work was conducted. This would be continued under Phase IIA to provide an element, which met the standardized HEPA test as conducted by ATI. A nickel alloy media would be found to meet that standard.

\section{Results of WSRC Testing}

Savannah River has provided a complete report on its investigation under Phase I, WSRC-TR-99000486, January $2000^{2}$. The testing indicated that the Mott sintered media could effectively filter the tank materials and be regenerated.

Typical test data are provided in Figures 4-1 to 4-3. The data shown is airflow rate through the element as a function of time. Three different test particles were used: sludge, South Carolina (SC) road dust and 
salt. The flow rate decreases with particle loading and then is restored (increases) after a backwash operation.

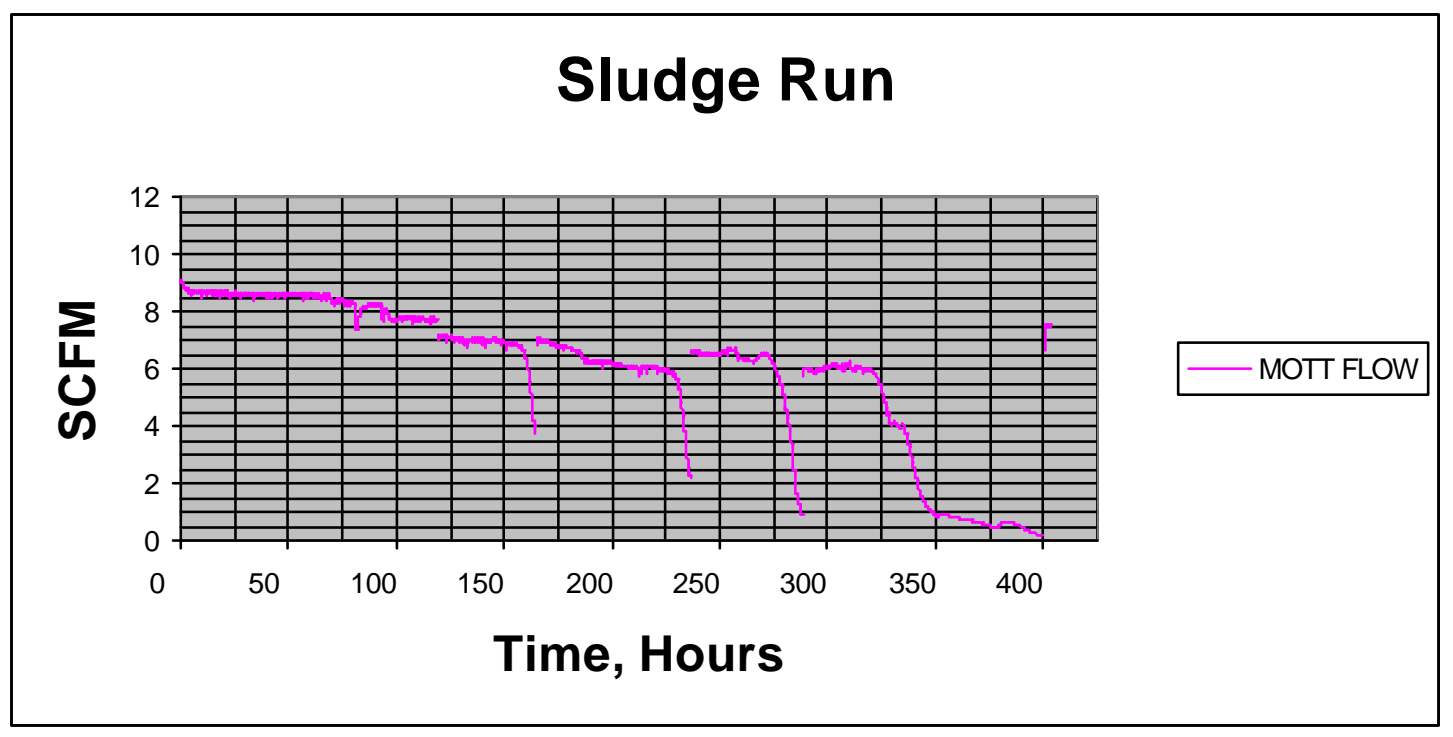

Figure 4-1 SRTC sludge test data.

\section{SC Road Dust Challenge Test}

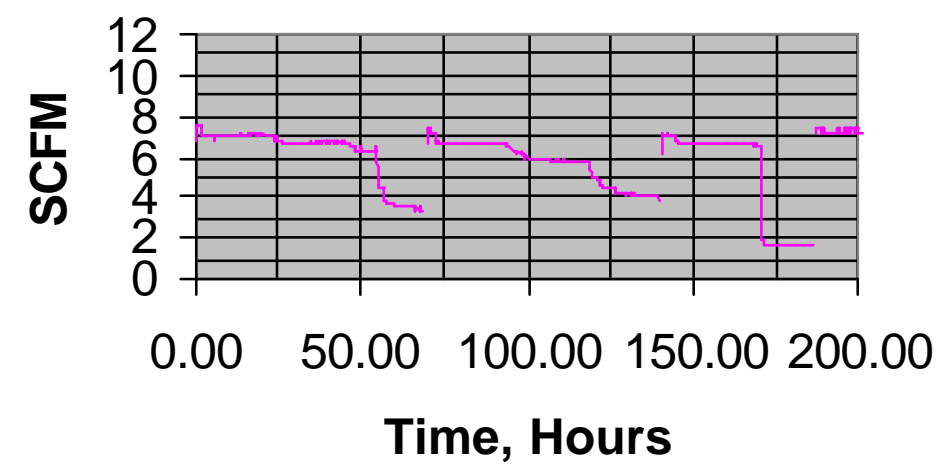

Figure 4-2 SRTC road dust data. 


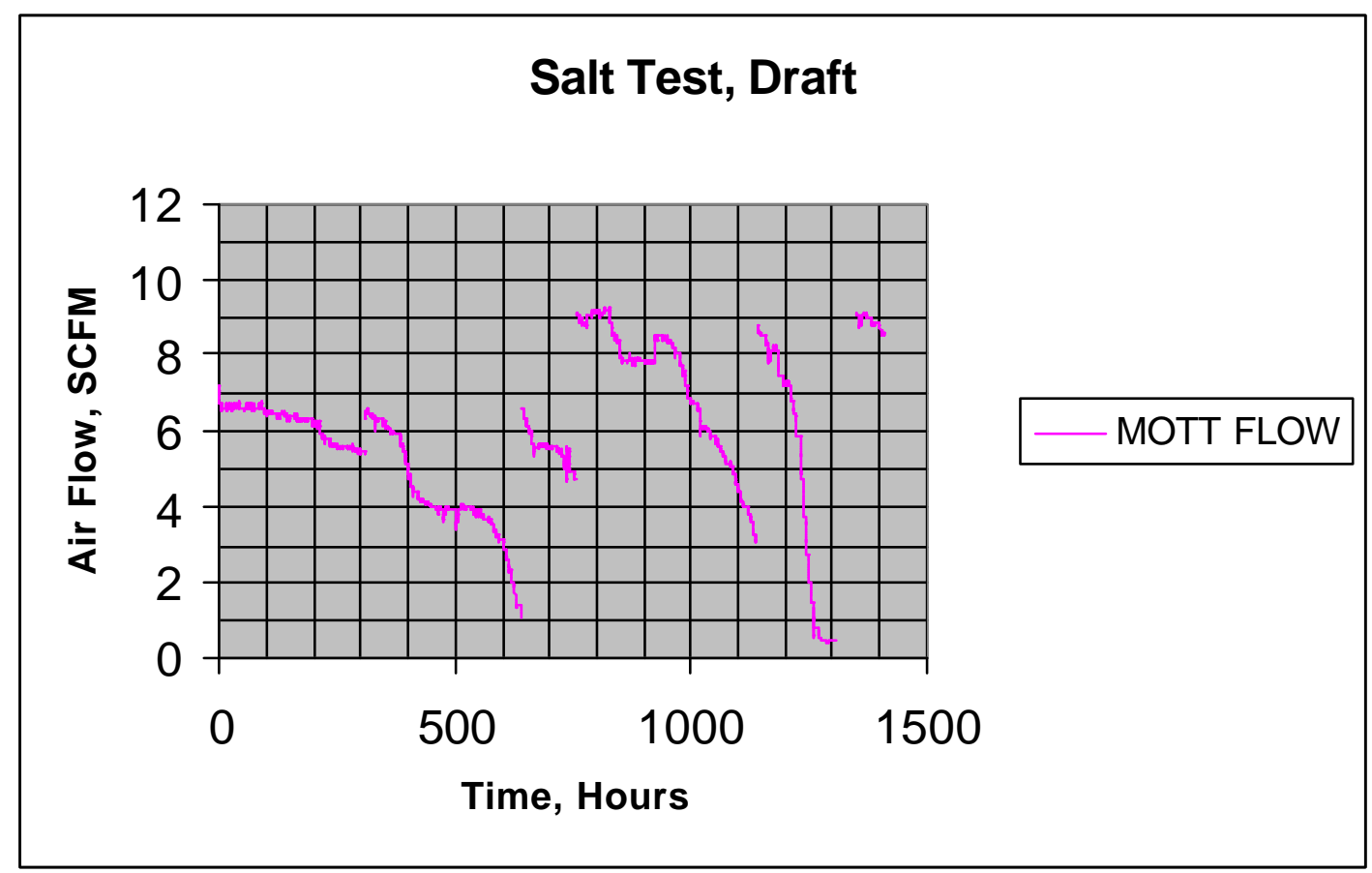

Figure 4-3 SRTC salt data.

\section{Conceptual Design for a Mott Regenerable HEPA Filter System}

The system proposed by Mott is based on existing technology applied to this application. Mott manufactures a variety of tubular filters, some filtering on the inside of porous sintered metal media. This technology was applied to the RHFS design.

The proposed system consisted of a single or dual Mott Hypulse GS filters incorporating liquid spray cleaning mechanisms, dual vacuum pumps for moving the gas through the filter from the waste tank, and a detached cleaning skid. The cleaning skid, capable of being transported to each HLW tank for cleaning filters, consists of tanks and a pump.

The Hypulse GS filter contains 13 porous metal elements, three inches in diameter, welded to tube sheets top and bottom, which are in turn welded into a housing shell. Each element has one high efficiency spray nozzle for cleaning. The element / shell assembly is connected to a cone bottom base. Tangential entry of the inlet gas creates a cyclonic effect, which will serve as an initial solids separator. Except for the body flange and spray nozzle connections, the filter is an all welded assembly. The entire filter body would be replaced if filter element replacement is ever required.

Two regenerative blower vacuum pumps provide the energy for vent gas movement and filter drying. They are constant operation pumps requiring no oil or water cooling. There are no waste streams generated. Reliability has been proven in countless industrial applications. A $33 \mathrm{HP}$ motor drives the pump.

The cleaning skid consists of three 50 gallon Nalgene tanks and one positive displacement air driven pump. The skid assembly is portable and is used to clean filters as needed. The tanks will hold acidic and caustic cleaning solutions, and water for rinsing. Compressed air is required for the pump. 
Instrumentation is provided to monitor filter pressure drop. The need for filter cleaning is indicated by a preset maximum pressure drop across the filter. Due to the nature of the vacuum pumps, flow measurement is not required. Pressure gauges provide a visual check of system operation.

The filter cleaning will be accomplished by a spray wash with an acidic cleaner, water rinse, caustic neutralization, water rinse, vacuum drying. In addition to the sprays, a reverse flow of air can assist in the cleaning by removing imbedded materials during the solution spraying. This feature provides the maximum cleaning flexibility possible. It is anticipated to require a total of 5 to 10 gallons per element to obtain effective cleaning.

Materials of construction for the filter are $316 \mathrm{~L}$ stainless steel. All piping exposed to the process gas is 316L stainless steel.

The system would be designed according to accepted ASME codes and specifications provided by SRTC and NETL.

Two single element prototype filters were built for regeneration effectiveness. One was delivered to SRTC and one was set up in the Mott laboratory. These filters would be further evaluated under Phase IIA of the contract.

The Mott filter design concept was accepted by the DOE as feasible and further work would continue under Phase IIA of the contract. A complete report on the Phase I work was issued on December, $1999^{3}$.

\section{PHASE IIA FULL SCALE REGENERABLE HEPA FILTER SYSTEM DESIGN}

\section{Full Scale RHFS Design}

The design for the Full Scale RHFS filter system is complete per the original Mott scope.

The Filter System Skid design is based on specification M-SPP-G-00300, Rev 0. and is comprised of the following components:

1. One Koch-Otto York Demister style 194, 304SS mesh with 304SS top and bottom rigid weld grids. All contained in a 304SS, 20" diameter x 10'-4" tall housing.

2. One Aerofin Type B non-freeze Steam Heating Coil. Model number BNF-14AE-29.0 x 24.0-1-1. Contained in an assembly housing of 304SS with dimensions of 34" x 34 " and transitions to 10" diameter for both inlet and outlet.

3. One Mott HyPulse GSM Filter System, catalog number XX2422-48-2.25-1-HDD. The design of the housing/vessel is complete. The design is per ASME section VIII, division 1 and the vessel is code stamped. The filter contains forty-eight (48) filter elements $21 / 4$ " diameter by 22" long, the housing diameter is 24". The new design provides 51 square feet of filtering surface area. Construction materials are stainless steel and Nickel; the filter elements being Nickel. The filter media is Mott precision porous metal meeting the HEPA efficiency rating. The housing includes a spray nozzle manifold for spraying the element inside surface. Blowback air is introduced into the clean side of the vessel for reverse flow.

4. The inlet and outlet nozzles have increased from the original 6" diameter inlet to a 10" diameter inlet. This was done to allow for the increase in flow from the original 400 CFM to the current 1000 CFM. The drain has also been increased from the original 4" diameter to the current 6" diameter. This is due to the increase in surface and the resulting increase in dirt holding capacity. In the following HEPA Filter, Figure 5-1, the design of the filter vessel can be seen. It shows the location of the elements, the conical bottom where the inlet to the filter is located, the drain, which empties into the HLWT. In addition, the modular design is clearly visible and shows the center section that may be removed for element change out. 


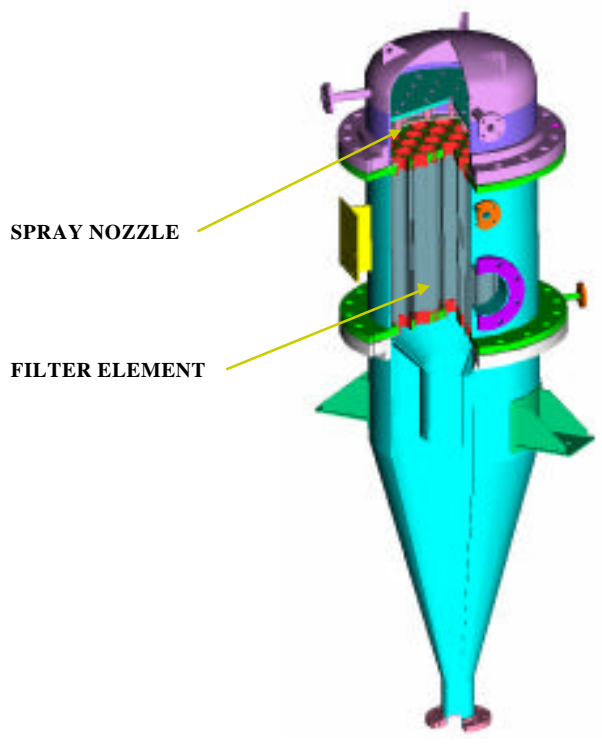

Figure 5-1 HEPA filter.

The nozzles for washing the inside of the elements remain the same and a new series of manifolds have been added to account for the additional elements. Figure 5-2 shows the alignment of the nozzle to the elements.

Figures 5-3 and 5-4 show drawings for the Hypulse GS filter and sintered metal element, respectively. A schematic diagram of the RHFS is shown in Figure 5-5. Figure 5-6 shows a typical skid layout.

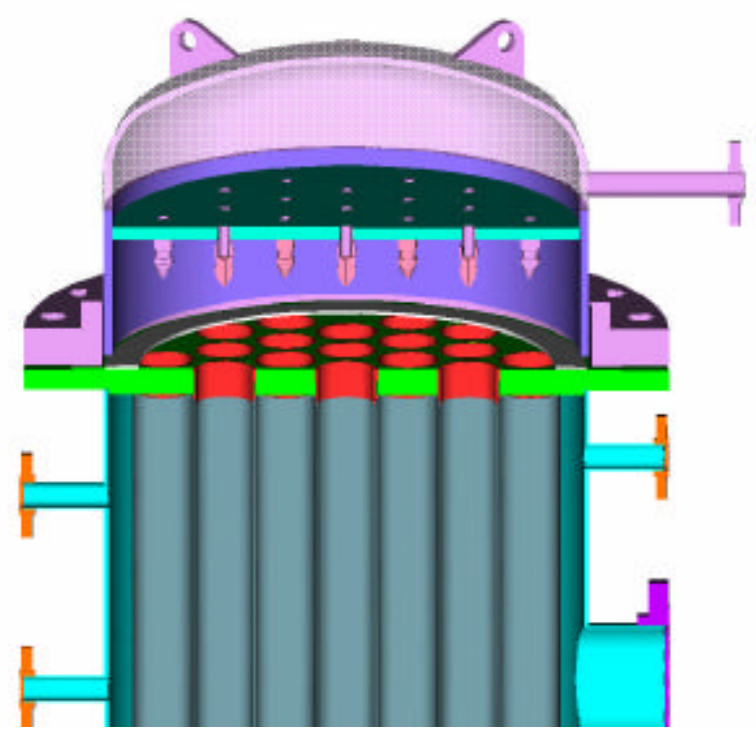

Figure 5-2 Filter spray nozzle location. 


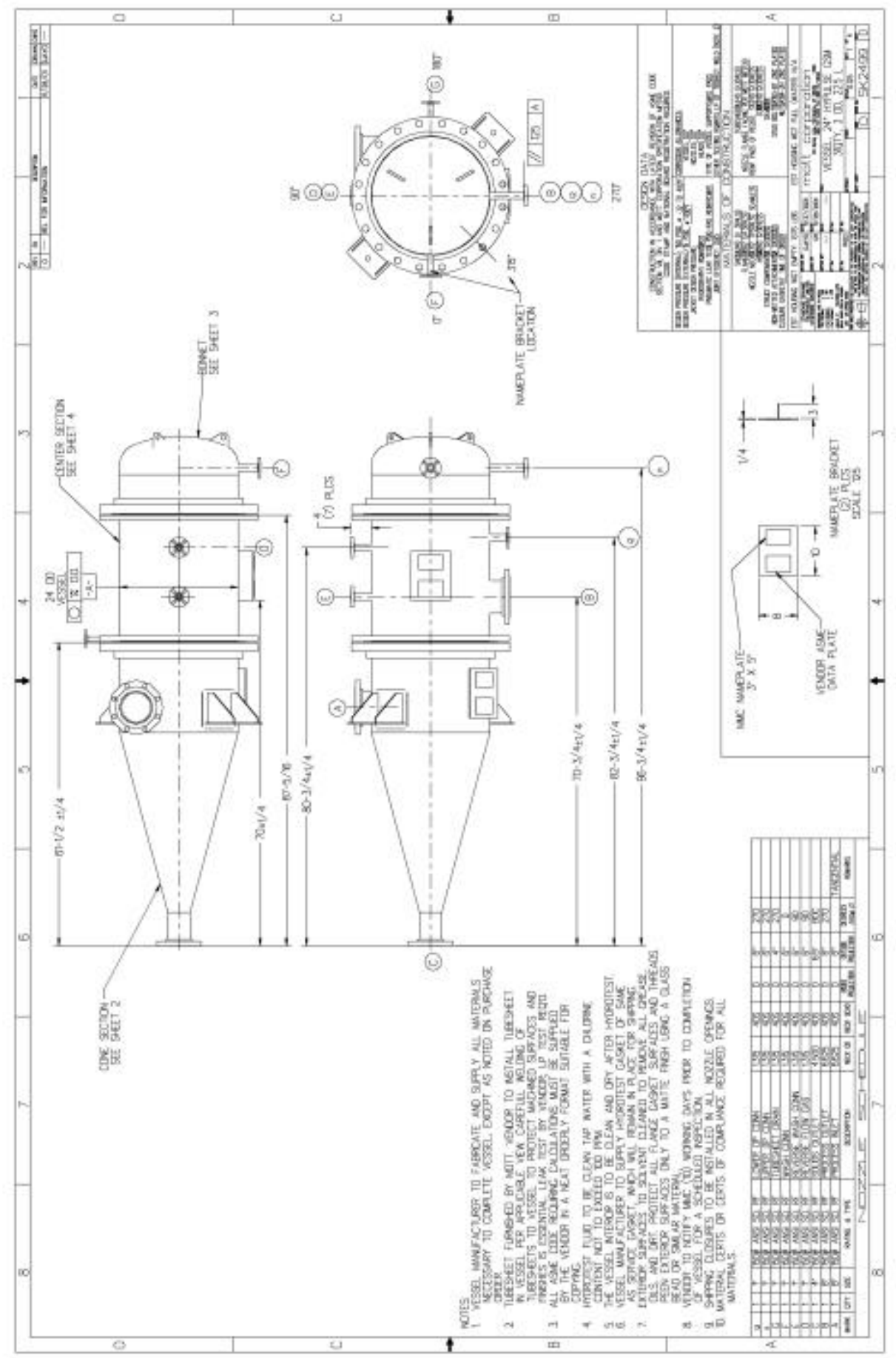

Figure 5-3 Hypulse GS filter drawing. 


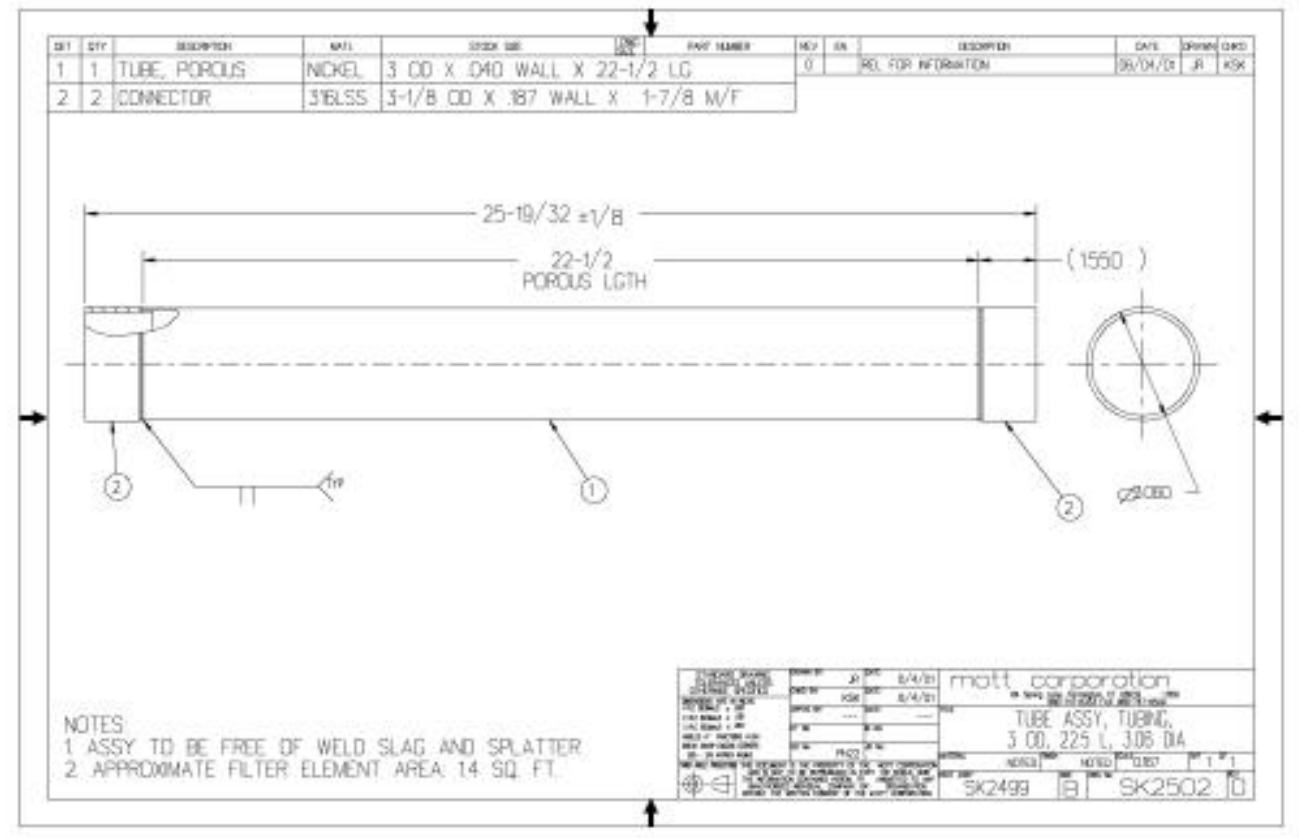

Figure 5-4 Sintered metal element drawing. 


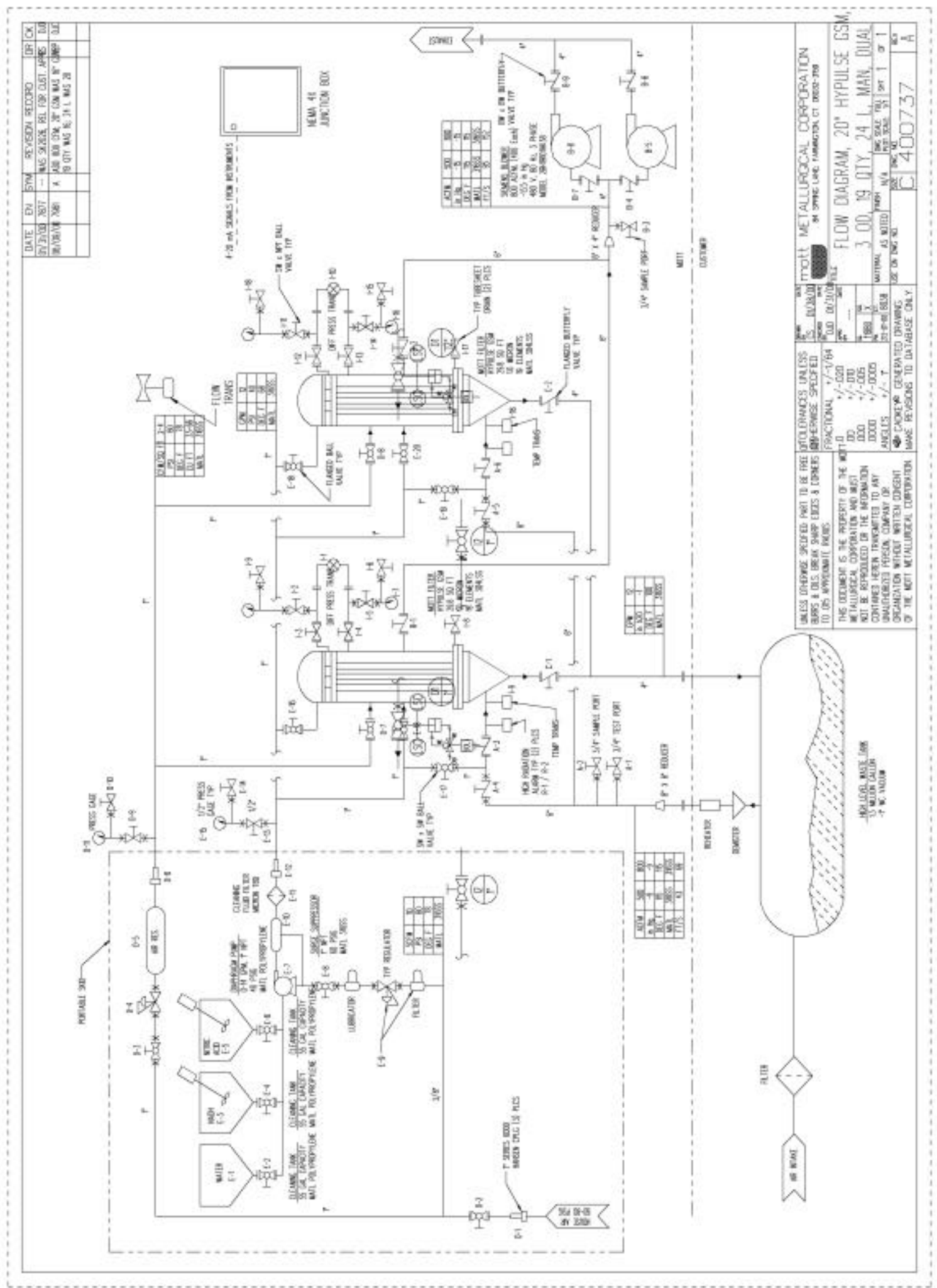

Figure 5-5 RHFS schematic diagram. 


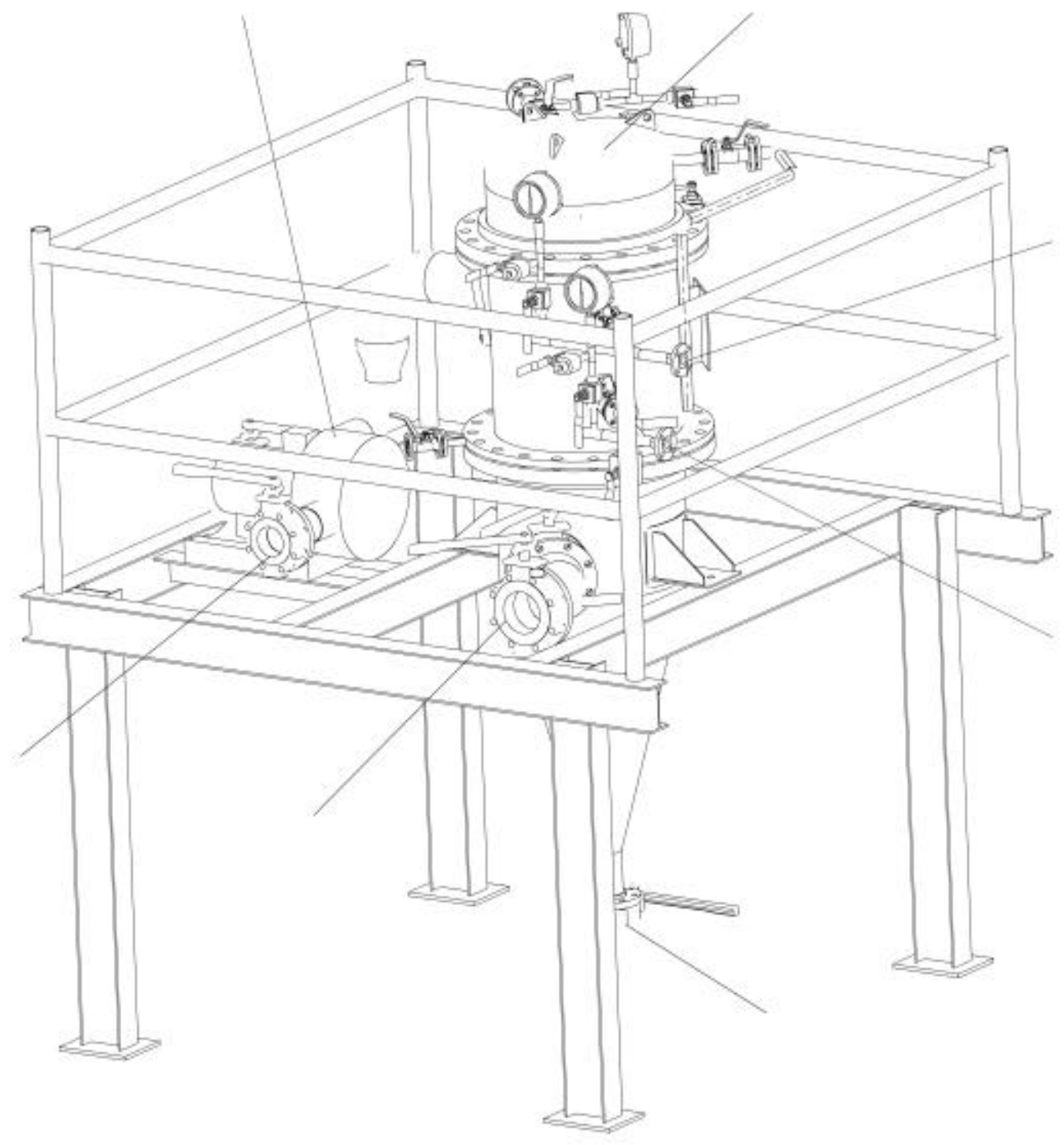

Figure 5-6 Typical skid layout. 
5. One Flanders HEPA filter model number BG1-2H1W-2GGF-304-D3 with Pureform filter elements.

6. One Gardner-Denver SutorBilt positive displacement vacuum blower model 6LP. Rated for 1000 CFM at 9" Hg.

7. Two 10" diameter manual valves. One for the inlet and one for the outlet.

8. One 6" diameter manual valve for the drain. The drain will empty into the waste tank.

9. Two Rosemont pressure transmitters for indication of terminal pressure drop. One instrument located upstream and one down stream.

10. All piping, lighting fixtures, insulation and labeling.

11. The entire system is mounted on a $7^{\prime}$ wide $\times 23^{\prime}$ long frame. The electrical control boxes are also included in this envelope dimension.

\section{Element Development}

The filter elements developed under Phase I were sintered 316L stainless steel, 3 inches in diameter. This element was evaluated both in the Mott Laboratory and WSRL for fouling and cleaning characteristics. This information has been reported in the Phase I Topical Report ${ }^{3}$.

However, since it was ultimately discovered that the stainless media did not meet the HEPA efficiency standard when properly tested, a new media was selected for further development and evaluation. A nickel media had been under development at Mott for some time and it was known to meet the HEPA efficiency standard. This media was further developed under Phase IIA for RHFS use.

The original element chosen was a 3" diameter nickel element, but this has proven to have a highpressure drop. The average pressure drop ranges from $70-80$ " water column (WC) at a flow of 30 CFM. This higher pressure drop is a direct result of the manufacturing process. Since the diameter is 3" diameter, in order to achieve proper mechanical strength and avoid premature collapse, the media has to be compacted using a higher pressure. In addition, the cleaning of the elements is a concern. With the denser wall, back pulsing using air is not nearly as effective as desired. This could lead to plugged filters and reduced cycle times. In order to improve this situation, a new element has been chosen for the filter system. The new filter is a $21 / 4$ " diameter x 22" long porous nickel product. Figure 5-7 illustrates the design of the element and shows the double open-ended construction.

This was a filter used in October, 2000 with positive results. The pressure drop data for this product is shown in Table 5-1.

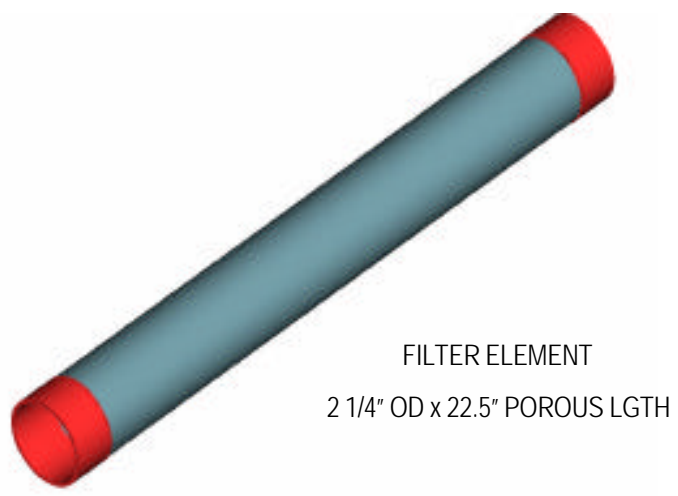

Figure 5.7 Filter element. 
Table 5-1

Nickel Media Air Flow

\begin{tabular}{|ccccc|}
\hline $\begin{array}{c}\text { Flow, } \\
\text { CFM }\end{array}$ & $\begin{array}{c}\text { Pressure, } \\
\text { Inch WC }\end{array}$ & $\begin{array}{c}\text { Pressure } \\
\text { Drop, inch WC }\end{array}$ & $\begin{array}{c}\text { Flowrate, } \\
\text { SCFM }\end{array}$ & $\begin{array}{c}\text { Velocity, } \\
\text { Ft/Min }\end{array}$ \\
\hline 14.8 & 27.3 & 27.3 & 13.81 & 13.41 \\
25.26 & 46.4 & 45.7 & 22.38 & 21.73 \\
30.96 & 56.2 & 55 & 26.68 & 25.9 \\
36.7 & 65.9 & 63.9 & 30.76 & 29.86 \\
42.6 & 75.4 & 72.6 & 34.71 & 33.69 \\
48.4 & 84.4 & 80.8 & 38.36 & 37.24 \\
\end{tabular}

As indicated in the Table 5-1, the pressure drop at 30 CFM is 55" W.C. as compared to $70-80$ " W.C. for the 3 " diameter element. This has prompted a change in design to the new element.

The design velocity for the filter system is $20 \mathrm{ft} / \mathrm{min}$ (FPM), which yields a clean pressure drop of about 42 " W.C. or 1.5 psi.

In addition, there is some data that seems to indicate that cleaning is easier with the smaller diameter element. This has to be confirmed in the laboratory.

The 2 1/4" diameter element has been tested by an independent lab and confirmed to meet HEPA standard.

\section{Element Tests at Oak Ridge}

Completed elements were sent to Oak Ridge TN where Air Techniques International (ATI) was conducting HEPA efficiency tests for WSRL. A housing was provided in which the Mott elements could be tested for HEPA efficiency as well as pressure drop.

Two nickel elements were tested at $33 \mathrm{cfm}$ with the following results:

$\begin{array}{ccc}\text { Element } & \text { Pressure Drop, psig } & \text { \% Penetration } \\ \# 1 & 3.4 & 0.001 \\ \# 2 & 3.6 & 0.001\end{array}$

HEPA standard is a penetration of less than $0.03 \%$.

These elements were the large diameter (3" diameter) elements and were sent to WSRL for challenge testing.

Following development of the more permeable nickel media in a smaller diameter element multiple manufacturing runs were made to determine the variability, if any, of the process on HEPA performance. In all 29 elements were manufactured and tested at Oak Ridge. Only one failed the HEPA test with a penetration of $0.032 \%$ versus a requirement of $0.030 \%$. The typical penetration was only $0.001 \%$. Airflow resistance at $25-35 \mathrm{cfm}$ was typically between 72 and 90 inches of water. These elements easily met the established criteria for both aerosol penetration and airflow resistance. The nickel elements had proven to be satisfactory for use in the RHFS process.

\section{Element Tests at WSRC}

Tests results for element evaluations performed during Phase IIA at WSRC are contained in the WSRC final report. ${ }^{4}$ Test data include the effect of particle loading and cleaning on pressure drop, pressure drop as a function of flow, and DOP test results. 


\section{Assessment of Proposed Technology}

The Mott sintered metal washable filter has been demonstrated in the laboratory to meet the criteria set forth for the design of a Regenerable HEPA Filtration System. The full RHFS requirements are set forth in the contract with the most significant criteria evaluated herein.

1. Provide a filtration efficiency of $99.93 \%$ of a 0.3 micron aerosol particle.

The Mott sintered metal filter elements provide at least this efficiency and have achieved efficiencies of $99.99 \%$.

2. Operate in a highly caustic environment.

The stainless steel vessel and piping materials, and the nickel filter media are resistant to high $\mathrm{pH}$ environments.

3. Operate in high humidity conditions.

The all metal filter is made of corrosion resistant alloys and are not affected by high humidity. The Mott filter is made to be cleaned with water solutions and is not affected by high levels of moisture.

4. Operate at temperatures ranging from $20-80^{\circ} \mathrm{C}$.

The all metal filter is capable of operating within the stated range and can withstand much higher temperatures, well above those encountered in normal use.

5. Be capable of filter media regeneration within the filter housing for many cycles.

The inside-out design provides for multiple methods of cleaning, including: spray washing; soaking and backflushing; reverse air flowing. The filter has shown in testing that it can be cleaned many times.

6. Have a useful life of 15 years for the filter elements.

Experience in other applications in industrial environments has indicated an almost indefinite life if the elements can continue to be cleaned.

7. Operate in radioactive environments.

The materials used in the Mott filter are compatible with nuclear materials and are routinely used in all areas of nuclear processing.

8. Operate at a flow rate of $800 \mathrm{CFM}$.

Meets the design requirement. It can, with higher pressure drop, operate upwards of that rate for short durations. Higher flow rates have not been evaluated.

9. Operate at low clean pressure drop.

The Mott filter, with nickel media, has been demonstrated to operate with clean pressure drops of only $80-90$ " water. The operating range of the filter to a fouled condition is over 250 inches of water.

The Mott filter has demonstrated that it can be regenerated when challenged with salt solution, South Carolina dust, and tank sludge. The test conditions are many times more sever than expected in actual service.

The filter incorporates a unique inside-out design that confines the contaminants within cylindrical elements allowing for easy and efficient cleaning. The filter also incorporates a cyclonic inlet to initially 
remove entrained particles and water drops by centrifugal force. This inlet has reduced the dirt load to the elements by up to $20 \%$ and should improve the duration between cleanings.

All of the testing and engineering evaluations have indicated that the Mott RHFS would be a satisfactory improvement over the existing glass fiber filters.

\section{Regulatory and Safety}

The design of the Mott RHFS is subject to all applicable design codes, including ASME VIII and IX, and any applicable nuclear codes. It is expected that it will meet all applicable regulatory requirements for similar types of equipment. Being an entirely enclosed system, it will comply with all environmental requirements.

The filter system is constructed as a metal housed filter with inert metallic filter elements which are durable in construction and not subject to degradation or mechanical failure. In operation, the system requires no local monitoring or operator attention. During filter element cleaning, manual operating valves are manipulated as necessary to move fluids to their appropriate destination. If desired some or all of these valves can be operated remotely. The installed location, on top of a HLW tank, provides a repository for cleaning materials into the waste tank. The volumes considered are small.

The mechanical reliability and integrity of the filter elements and the all welded seal design protect the atmospheric side of the filter. It is essentially a fail-safe design.

The mechanical blower that generates the vacuum to operate the system can be remotely located in a shed or other structure to minimize noise levels. Since it operates at higher discharge pressures than the current blowers, it can be located some distance away from the tank for easier access and maintenance.

The exposure to radiation and other unhealthy materials is greatly minimized with the Mott RHFS. With a 15 year operating life human exposure is greatly reduced when compared to change outs and handling of the glass fiber HEPA filters. A Human Factors Assessment Report was prepared and reviewed by the International Union of Operating Engineers National Hazmat Program in September 2002, Report Number OENHP 2001-18 Version A.

The Mott Corporation feels the new sintered metal RHFS would be a significant improvement over the existing glass fiber technology and overcomes most, if not all, of the deficiencies of the existing filters.

\section{Project Reviews}

Two formal project reviews were conducted during the life of this project. Each involved approximately 6 hours of oral presentations, coupled with written materials.

The first occurred in September 2000 at Richland, WA, as part of an American Society of Mechanical Engineers (ASME) Peer Review of the Alternative Filtration Program at DOE. The outcome of this review included a favorable review by the ASME review panel. Details of this assessment are presented in Reference 5.

The second review occurred on December 11, 2001 at the Savannah River Research Campus in Aiken, SC. This review covered the proposed full-scale design of the system and all development work. Details of element development, element testing and full-scale system design were presented. The International Union of Operating Engineers National Hazmet Program also conducted a human factors assessment of the system. Details of this assessment are presented in Reference 6.

\section{CONCLUSIONS AND RECOMMENDATIONS}

This DOE project, to evaluate new technologies to replace the existing glass fiber HEPA filters, has progressed through a series of steps, each being satisfied before moving on to the next phase. The feasibility of using cleanable permanent filter media has been demonstrated, and a full-scale system design has been submitted and reviewed by both DOE and WSRC with approvals. 
Prototype filter designs have been successfully tested and evaluated and have resulted in confidence that the filter design meets the performance criteria established. The design is rugged, reliable, and consistent with mechanical designs typically used in nuclear facilities.

The chosen filter media, a sintered nickel, meets and exceeds the HEPA filtration efficiency standard of $99.97 \%$ removal of 0.3 micron aerosol particles, typically achieving $99.99 \%$ removal. It also has a low pressure drop of 80-90 inches of water at design gas flow velocities.

Simulation particle challenge testing was successfully performed which demonstrated the capability of the filter to remove solids and regenerate on cleaning. The simulation challenge was significantly more severe than the expected operating conditions on HLW tanks.

It is recommended that a full-scale demonstration unit be installed on a HLW tank for extended operation where actual operating conditions can be evaluated. This would complete the final phase of testing and evaluation before a final design is approved for installation on all tanks currently using glass fiber HEPA filters.

\section{REFERENCES}

1. Adamson, D. J., "Experimental Investigation of Alternative In Situ Cleanable HEPA Filters", WSRC-TR98-002382, October, 1998.

2. Adamson, D. J., "Experimental Investigation Of Alternative In Situ Cleanable HEPA Filters", WSRCTR-99-000486, January, 2000.

3. Sekellick, R. S., Mott Corporation, "Development of Regenerable HEPA Filter System", Topical Report, Phase I. Part 1 and 2. RFP No. DE-AC26-99FT40570, December 28, 1999.

4. Adamson, D. J. "Alternative HEPA Filter Full Scale Single Element Testing", WSRC-TR-2002-00238, September 2002.

5. ASME Peer Review, "Alternative Metallic High Efficiency Particulate Air Filtration System" ASME/CRTD-RP-0015, September 2000.

6. International Union of Operating Engineers National Hazmat Program, Human Factors Report, "Alternative HEPA Filtration, Mott Corporation" DOE TMS \#2091, OENHP\#2001-18 Version A. September 2002. 


\section{ACRONYMS AND ABBREVIATIONS}

\begin{tabular}{ll}
$\begin{array}{l}\text { Acronyms } \\
\text { and } \\
\text { Abbreviations }\end{array}$ & \multicolumn{1}{c}{ Definitions } \\
ATI & Air Techniques International \\
CFM & Cubic Feet per Minute \\
DOE & Department of Energy \\
DOP & Di-octyl phthalate \\
FETC & Federal Energy Technology Center \\
FPM & Feet per Minute \\
GS & Gas/Solid \\
HEPA & High Efficiency Particulate Air (filter) \\
HLW & High Level Waste \\
HLWT & High Level Waste Tank \\
RHFS & Regenerable HEPA Filtration System \\
SCFM & Standard Cubic Feet per Minute \\
SRTC & Savannah River Technology Center \\
WSRC & Westinghouse Savannah River Company \\
WSRL & Westinghouse Savannah River Laboratory \\
&
\end{tabular}

Rev. 11/27/02 